\title{
1. The philosophical foundations of financial ethics
}

Kara Tan Bhala

The foundation of financial ethics is moral philosophy, a profound subject with a majestic canon going back two and a half millennia. This canon guides us to right actions in life as it does in finance. The purpose of this chapter is to give a reasonably detailed overview of these philosophical foundations and propose that the established moral theories are relevant and applicable in the practical field of finance. There are reasons why financial ethics has lost its place in academic finance, and therefore in the practice of finance, and this chapter will elaborate on the causes. It is not overly optimistic to state that the rediscovery of ethics in finance has already begun.

\section{DEFINING ETHICS}

The reader should not get too mired in the difference in meaning of the terms "ethics" and "morality" because this abstruse problem is only a concern for professional philosophers. For the rest of us, the terms may be used interchangeably. Ethics derives from the Greek word, "ethos" which means traditional practice. Morals or morality derives from the Roman "mores" denoting custom. Morality has come to be associated with heavy-handed religion of the impositional variety. Hence, the term has fallen into disuse in modern parlance as it has negative connotations.

The term ethics as used today means to do the right thing. Rachels' more formal definition of ethics is "at the very least, the effort to guide one's conduct by reason - that is, to do what there are the best reasons for doing - while giving equal weight to the interests of each individual affected by one's decision." "Clearly, the proper practice of ethics requires three elements: a moral agent, reason and action.

First, ethics requires a moral agent, the individual who is doing the moral act. The moral agent does not necessarily have to be a human person. The agent may, arguably, be a corporation. The characteristic presumed in moral agency is freedom. We have to be free to choose to act ethically. Otherwise, if we act badly and do the ethically wrong thing, then we are not morally blameworthy. If we did not have free will, our moral actions cannot either be blamed or praised because we are not responsible for our actions.

Secondly, ethics requires reasoning. Ethical judgments must be backed by good reasons. It is usually unwise to allow emotions as ethical guides because ethics will simply become a preference such as liking the color red over the color yellow. Emotions may be irrational, products of prejudice, or cultural conditioning. For instance, people used to feel it was ethi-

1 James Rachels and Stuart Rachels, The Elements of Moral Philosophy (7th edn, McGraw Hill 2012) 13. 
cally right if women could not vote. Therefore, to discover the truth, it is best to let emotions be guided by reason. The ethically right thing to do is always supported by sound arguments.

Thirdly, the contemporary use of "conduct" when referring to ethical behavior in banking and finance finds its roots in the word "action". Ethics requires action. For Aristotle, a person does not become virtuous simply by thinking about virtue. She must choose a virtuous action and then carry out that chosen act.

Humanity has been concerned with doing the right thing for millennia and philosophers over the centuries have given us comprehensive and well thought out theoretical frameworks to help in this quest.

\section{A SHORT HISTORY OF ETHICS}

Ethics is one of the five fields of classic philosophical exploration. Each of the five specialties, with a succinct description, are given below:

1. Epistemology: How and what do we know?

2. Metaphysics: What is the nature of being?

3. Politics: How shall we govern ourselves?

4. Ethics: How shall we live?

5. Aesthetics: What is beauty?

Clearly, moral philosophy has an impressive lineage. This segment of philosophy is the attempt to understand the nature of human values, of how we ought to live and what constitutes right conduct. ${ }^{2}$ Ethics perhaps, begins with Socrates asking the celebrated question, "How shall we live?" For Socrates and the Ancient Greek philosophers, the way to happiness or eudaimonia was to live a life of virtue. Eudaimonia is perhaps best described as flourishing or a well-lived life. Socrates sketched out a theory of what we now call virtue ethics, but it was Aristotle who took the theory to higher levels of sophistication and detail. In virtue ethics, whether an act is right depends on the character of the moral agent who performs the act. A person who possesses virtues such as courage, justice and generosity, is a virtuous person. There is a fuller discussion of virtue ethics later in this chapter.

Skipping ahead a few centuries to the medieval philosophers, St. Thomas Aquinas and the scholastics incorporated Aristotle's virtue ethics into their Christian moral theology. The Natural Law approach of Aquinas attempts to bring together Aristotle's idea that everything should fulfill its natural end or purpose. In fulfilling our purpose we achieve the supreme good. For Aquinas, God gives purpose or telos and instills in humanity a comprehensive view of what is natural and right. According to Natural Law, human reason endowed by God is a starting point for morality. The use of reason allows us to arrive at the same moral truths as are given through divine revelation. There should be no contradictions. The Natural Law approach dominates Catholic moral thinking. Yet, as Natural Law is based on reason, it is in principle discoverable by anyone, whether religious or not. For the same reason, it is universal, rather than culturally conditioned.

\footnotetext{
2 Richard Norman, The Moral Philosophers: An Introduction to Ethics (2nd edn, Oxford University Press 1998) 1 .
} 


\section{Research handbook on law and ethics in banking and finance}

A number of centuries later, during the Enlightenment, the most influential moral philosophers to arise at that time were Thomas Hobbes (1588-1679), David Hume (1711-76), Jeremy Bentham (1748-1832), John Stuart Mill (1806-73) and of course, Immanuel Kant (1724-1804). Hobbes thought ethics should be based on a contractual agreement between people, hence the creation of the idea of a 'social contract'. Hume proposed that ethics is based on sentiment rather than reason because people are able to have a natural sympathy for others. Bentham was the founder of modern utilitarianism and Mill later refined the theory by differentiating between the different pleasures. The utilitarians propose that ethics should be based on the expected results of action. In response to Hume and his emotivist ethics, Kant developed a magnificent moral system that is described as "deontological" or duty based. According to Kant, fundamental ethical principles can be based on pure reason alone. Kant stands at the pinnacle of the Enlightenment period. Other moral philosophers of note followed that period when human reason and the idea of human progress were idealized. In the nineteenth and twentieth centuries, Friedrich Nietzsche and Jean Paul Sartre, often labeled as existentialists, considered ethics in the light of the self-development of individuals, or the personal questions people ask. Their methods of moral philosophy fall within the category of the continental tradition.

A different ethical discourse was taking place in the US and UK. For much of the twentieth century ethical theory in the so-called Anglo-Saxon tradition was dominated by arguments about whether ethical language was meaningful. The predominant type of ethical inquiry during the post-modern period is called meta-ethics, a branch of analytic philosophy that focuses largely on the language of moral discourse. So, while the past couple of millennia were devoted largely to normative ethics that was concerned with the question, "What kinds of action are good or right?" the past century or so of meta-ethics focused on the question, "What is it to say of an action that it is good or right?"

In the last three decades, there has been a revival of interest in applied ethics. Scholars now work on theories of social contract, virtue ethics and re-examining earlier ethical arguments. It became clear that meta-ethics was interesting mostly to academic philosophers and did not help people with practical ethical problems. Thus, meta-ethics in particular and philosophy in general were marginalized in society due to a large measure of irrelevance.

\section{DEFINITIONS OF TERMS}

To avoid confusion, the ethics terms in common usage and in this chapter ought to be defined.

Ethical - To behave ethically is to conform to a set of ethical norms, whether personal, religious or established by a society, group, or profession.

Unethical - An act is unethical if it goes against a professed set of norms. We use reason to assess whether an act is unethical.

Amoral - An act is amoral with respect to the entity that performs it. For the entity, there is no reference to any moral perspective or to any values that may result in a moral perspective. For example, a cat does not (debatably) have a sense of right and wrong. A person suffering from a mental condition and incapable of understanding right from wrong is

3 Norman (n 2), 1. 
amoral. A human person of normal mental capacity, embedded in a group or culture, who does something wrong has acted unethically, in that instance, not amorally.

\section{FINANCIAL ETHICS}

Ethics in finance is applying moral norms to financial activity broadly conceived. It is crucial that finance be conducted according to moral norms because of the vital role "financial activity plays in the personal, economic, political, and social realms but also because of the opportunities for large financial gains that may tempt people to act unethically."4 Unfortunately, while ethics is two-and-a-half millennia old, the subject of financial ethics is relatively young, less than a couple of decades. One of the first academics to devote a textbook to financial ethics is John Boatright. His book, Ethics in Finance is now in its 3rd edition and a fine reference for practitioners and students. Yet, his is one of a handful of books on the subject taught in a handful of business schools. Business ethics became a required core course for accreditation of MBA programs after the Enron scandal. Oddly, financial ethics courses have not been similarly mandated after the much more damaging Global Financial Crisis (GFC) of 2008.

Financial ethics falls into the area of applied ethics. We mentioned normative ethics and meta-ethics in the previous section. The other two sub-categories of ethics are descriptive ethics and applied ethics. The former describes the moral choices and values in a particular society. For example, we may describe the veiling of women in certain societies or how some societies allow girls younger than 16 years to be married. A key feature of this form of ethics is its complete lack of examination or questioning of issues of right and wrong. It describes but does not prescribe. Thus, descriptive ethics does not help with finding the right ethical choice in any ethical issue.

The other category, applied ethics, advanced as various fields of human endeavor flourished. For example, distinct and recognized areas of applied ethics include medical ethics, environmental ethics, feminist ethics and legal ethics. It is therefore, surprising that finance as a long and well-established undertaking should only recently have an association with ethics. There are several reasons for this peculiarity. They can be classed under two sections: (1) reasons inherent in moral philosophy itself and (2) reasons found in standard orthodox finance theory.

\section{(1)}

\section{Issues Inherent in Ethics}

\section{The problem of objectivity}

One reason for the emergence of meta-ethics in the twentieth century is the fear philosophers had of being arbiters of values and the best way to live for others. They feared being labeled preachers. Behind this fear is the view that moral philosophy cannot establish correct theories about how a person ought to live or act because no one can do so. According to this view, there is no one correct view about how we ought to live because beliefs about such matters cannot properly be said to be true or false. People and cultures differ from one another in their basic attitudes towards good or right. Philosophy cannot in principle resolve the disagreements. Thus, arose the doctrine of ethical relativism and the problem of objectivity (or lack thereof).

4 John R. Boatright, Ethics in Finance (3rd edn, Wiley Blackwell 2014) 14. 


\section{Research handbook on law and ethics in banking and finance}

\section{Ethical relativism}

When philosophers threw in the towel on moral philosophy developing an objective theory of ethics, most of the learned and the leaders of society seemed to do so as well. Hence, the teaching of ethics in public schools was in large measure, abandoned. The problem was deciding which ethical tradition to teach because school authorities did not wish to privilege one culture or group's moral system over another. Yet, this wholesale discarding of ethics training and education is too extreme. Relativist arguments are not indefeasible and there are ways to refute cultural relativism.

The basic proposition of cultural relativism is, different cultures have different moral codes. There is not a way to decide which is right or wrong. There is no sub specie aeternitatis a view from the eternal or simply put, a universal perspective. Thus, the moral codes across cultures are simply different, none are right and none are wrong. The idea of universal truth in ethics is fallacious.

The cultural relativism proposition has, paradoxically, become accepted truth in the West. Of course, the proposition cannot be true because according to cultural relativism, there is no objective truth in ethics. Therefore, the proposition that there is no objective truth in ethics cannot be an objective truth but merely one of many moral statements out there that are neither wrong nor right. Just by this logical move, the cultural relativism argument is defeated. However, this glaring logical flaw has not stopped the spread of the idea there is no objective moral code. Consequently, its popularity has led to the decline of ethics education and discourse. This line of (faulty) thought, more than any other, has persuaded people to be skeptical about ethics.

There is another way to refute the cultural relativism argument. Here is the general logical structure of the cultural differences argument: ${ }^{5}$

1. Different cultures have different moral codes.

2. Therefore, there is no objective truth in morality. Right and wrong are only matters of opinion, and opinions vary from culture to culture.

This argument is not valid. Valid arguments require the conclusion (2) must logically follow from the premise (1). In the cultural relativism argument, the conclusion does not follow from the premise. Even if the premise is true, the conclusion is still false. Just because two cultures disagree, it does not follow that there is no objective truth in the matter. The objective truth may be out there but we have not found it. The objective truth may be a moral code of one of the cultures, but we do not know that yet. The argument tries to derive a substantive conclusion (there is no objective truth in morality) from the mere fact that cultures differ. This is impossible. The conclusion does not follow from the premise. The cultural relativism argument is invalid. Thus, the argument fails.

Suppose the cultural relativism argument is true. This means that:

1. We cannot criticize morally egregious acts such as torture, female infanticide and cultural genocide.

2. The idea of moral progress is called into doubt, see for example equality for women. For most of history (and even now in many parts of the world), women were subjugated,

$5 \quad$ Rachels and Rachels (n 1), 18. 
oppressed and lacked equal rights with men. If cultural relativism is correct, can increasing equality for women be viewed as progress? Moral progress is to replace old ways with new, improved ones. By what standard do we judge the new ways better?

These straightforward arguments against cultural relativism should lead to its rejection. After all, slavery is wrong wherever it occurs, and a culture can make fundamental moral progress. Because cultural relativism implies these judgments make no sense, the idea cannot be right.

\section{The influence of scientism}

Despite the refutations to relativism, people are still attracted to ethical subjectivism. One reason is that people think ethics, unlike science, does not have proofs. In an age of science, people expect scientific-like proof to solve important problems. Yet, the methods of science and the methods of ethics are different. Science uses the empirical method that involves experimentation and observation. The researcher gets data to support or refute a theory.

Even though ethics does not use the scientific method it is no less rigorous. The method of ethics is discursive which means to proceed by argument and reason. We used the same method in the previous section where we refuted the cultural relativism argument. From that process, the discursive method can be generalized as follows:

1. Give reasons to support a proposition about an act being right or wrong.

2. Analyze arguments.

3. Justify principles.

In the end, there may be good reasons to support an argument but it may be difficult to persuade some people to agree with the opinion. It is unlikely most arguments will receive unanimous agreement. It is particularly vexing when the examples given to support that "proof" in ethics is impossible are the ones involving supremely difficult moral issues such as abortion or euthanasia. In practice, ethical issues are far more quotidian and uncomplicated.

\section{Issues Inherent in the Orthodox Finance Model $^{6}$}

Finance views itself as a positive science and as such, value neutral. The subject also has been influenced by the reverence for the methods of science. Accordingly, finance in its current state, is confined to facts, drawing empirically testable propositions from them. Neither academics nor practitioners endeavor to offer normative, that is, value-based prescriptions.

The separation of facts from moral values in economics is called the "separation thesis." Milton Friedman, the Nobel Laureate for Economics, propounded and popularized this theory. $\mathrm{He}$ is known for saying "Positive economics is in principle independent of any particular ethical position or normative judgments." "Finance is an offspring of economics and it follows finance scholars and professionals apply the separation thesis to their specialty. Consequently, since Friedman, a period of roughly 60 years, there has been little or no space for ethics in the theory and thus, the practice of finance.

6 Kara Tan Bhala, "Mission" (Seven Pillars Institute for Global Finance and Ethics, March 17 2010) https://sevenpillarsinstitute.org/mission, accessed on September 172015.

7 Milton Friedman, "The Methodology of Positive Economics" Essays in Positive Economics (Chicago, IL: University of Chicago Press 1966). 


\section{Research handbook on law and ethics in banking and finance}

The orthodox model of finance is Modern Finance Theory or MFT. This theory is based on what is often termed, neo-liberal economics. Essentially, MFT comprises three models:

1. The Efficient Market Hypothesis.

2. The Capital Asset Pricing Model.

3. The Options Pricing Theory.

MFT makes five major assumptions:

1. Economic agents are always rational.

2. Rational agents are purely self-interested.

3. Rational agents aim only to maximize utility.

4. Utility is distilled to economic utility, i.e. profits.

5. Therefore, rational agents aim to maximize profits.

These are mere assumptions and were originally made to simplify a complex world in order to develop predictive quantitative models. Naturally, the assumptions do not capture the richness and complexity of the real world. For example, numerous experiments show people are not motivated purely by economic profit but also by values such as fairness and trust.

Over time and constant habitual use, the assumptions have evolved from:

a. "assume" (assume agents are rational, self-interested and aim to maximize profits) to,

b. "is" (agents are rational, self-interested and do aim to maximize profits) to,

c. "ought" (agents ought to be rational, self-interested and ought to aim to maximize profits.)

The assumptions of profit maximization behavior and an efficient market have replaced any need for ethical discourse to resolve ethical questions in theoretical finance. Hence, the conventional wisdom has been that markets decide efficiently and ethics is meaningless in finance.

MFT has served us well in systemizing a broad field and providing a simple framework but the theory and its assumptions have become entrenched and attained a vaunted status as the orthodox ideology. Since the GFC, questioning the primacy of neo-liberal economics-based finance theory has begun. Practitioners are more willing to speak of ethics in finance, urged on, no doubt by regulators and the public.

\section{PURPOSE IN FINANCE}

The first step in establishing ethics in finance is to borrow a doctrine of Natural Law and state a purpose for finance. Purpose is the end towards which actions are directed. Purpose guides actions. A noble purpose is more likely to engender good acts, although it does not guarantee every act will be good.

Finance aspires to be a profession but all professionals seek purpose in their work. Most professions have well-articulated, aspirational purposes. For example, doctors and nurses help people to be healthy. Lawyers help obtain justice. Teachers help people learn. Priests help people spiritually. The finance profession should therefore, profess a purpose. One suggestion for a statement of purpose is: 
The purpose of finance is to help people save, manage, and raise money. ${ }^{8}$

Finance should have its purpose enunciated and accepted. Students in finance should learn it in their business education. Perhaps the purpose should be taught even at elementary school. Practitioners should be comfortable with the purpose of finance, knowing it implicitly and speaking it unabashedly. This acceptance and acknowledgement is a first step towards improving the culture of finance. Yet another step in the progress towards an ethically educated finance culture is the understanding of the main ethical theories.

\section{ETHICAL THEORIES}

What is an ethical or moral theory? "Moral theories attempt to systematize ordinary moral judgements, and to establish and defend basic moral principles." ${ }^{9}$ We need ethical theories because simply listing a series of rules of dos and don'ts is not sufficient. The theories give us clarification and a decision procedure for resolving difficult or complex cases, or in other words, a working framework for ethical practice. In new situations of financial practice the theories help to explain and give justifications for a chosen act that is deemed ethically right. Using these frameworks and standard techniques allows us to practice and hone our moral reasoning. We become more adept at moral argumentation, which enables us to "take part in corporate discussions or public policy discussions in an intelligent way, with knowledge of how to present and evaluate moral arguments." ${ }^{10}$ In sum, think of ethical theories as tools for solving ethical problems.

This chapter describes four major ethical approaches: (1) Utilitarian Theory, (2) Deontological Theory, (3) Justice Theory, and (4) Virtue Ethics Theory.

\section{UTILITARIAN THEORY}

Jeremy Bentham is the father of modern utilitarian theory. This form of ethical theory is a branch of ethics called consequentialism, which proposes the consequences of an action are all that matter when taking an ethical decision to act. The rightness or wrongness of an action depends on the consequences of the act. Consequentialist theories have been around for a long time. Elizabeth Anscombe coined the term "consequentialism" in her essay "Modern Moral Philosophy" in 1958. Utilitarianism is by far the most widely known form of consequentialism, and there is often confusion when distinguishing the two.

Teleological is the classical term for ethical theories that focus on outcomes, or ends, to determine correct ethical action. Teleology comes from the Greek words, "telos" meaning, "end" and "logos" meaning, "science." Before Anscombe, utilitarianism was the more general term for teleological ethical theories. Today, consequentialism is the most widely accepted

8 Kara Tan Bhala, "The Purpose of Finance" (Seven Pillars Institute for Global Finance and Ethics, January 22 2013) http://sevenpillarsinstitute.org/mission/the-purpose-of-finance, accessed on September 162015.

$9 \quad$ Richard T. De George, Business Ethics (6th edn, Pearson Prentice Hall 2006) 49.

10 De George (n 9), 50. 
umbrella term, containing distinguishable sub-categories with a broad variety of desired outcomes.

For classical utilitarianism the desired outcome is creating the most good for the most people or maximizing the overall good. Both Bentham and Mill had the idea that good is associated with pleasure or happiness, which is a hedonistic view. Classical utilitarianism guides ethical decisions that bring the most pleasure or happiness for the greatest number of people. In sum, the Principle of Utility is:

In all circumstances we ought to produce the greatest happiness or well-being for the greatest number.

In assessing the outcomes of an action the only thing that matters is the amount of happiness or unhappiness created. Everything else is irrelevant. Notably, each person's happiness counts equally and we cannot privilege our happiness or that of loved ones above the happiness of others. This makes the utilitarian approach universalistic.

Bentham was a pure and simple hedonistic utilitarian. In his view, happiness should be measured in terms of duration, intensity, how near, immediate and certain it is and how free from pain and how likely it is to lead on to further pleasure. These considerations are measured in 'The General Utilitarian Analysis' below. Bentham also thought that acting according to the Principle of Utility would itself bring pleasure and happiness. The principle can be followed for the intrinsic pleasure as well as for the benefit to others.

Mill refined Bentham's model to distinguish between higher and lower qualities of well-being. According to Mill's form of utilitarianism, we should seek to maximize higher forms of well-being rather than lower ones. There is a ranking of the value of various pleasures. The Millsian hierarchy of pleasures places sensual pleasure at the bottom and the pleasures of the mind at the top, so moral and intellectual pleasures are best while sensual pleasures are least good. Mill's utilitarianism has both a qualitative as well as a quantitative aspect. An obvious criticism of this refinement is one person's higher pleasure is another's lower pleasure and not everyone thinks listening to Beethoven's fifth piano concerto constitutes a higher form of well-being. Mill also goes beyond Bentham when he gives a positive place for rules within the overall utilitarian approach.

\section{Rule Utilitarianism}

The chief exponent of modern rule utilitarianism is Richard Brandt. After countless utilitarian evaluations of certain acts, it is possible to frame general rules. The rules may then be used in assessing a similar type of act because these rules apply to classes of actions. When evaluating the ethics of say, lying for personal economic gain, we can determine that lying under these circumstances is wrong simply by observing the consequences in the past. Thus, we may apply this rule, "Lying for personal gain is unethical" to a conduct that falls into this category without the need for performing the steps of a utilitarian calculation.

We also can make a distinction between strong rule utilitarianism and weak rule utilitarianism. The former holds that a person should never break a rule that is established on utilitarian principles. The latter states there may be circumstances when the outcome of a particular act may take precedence over the general rule in a utilitarian assessment, although that rule still needs to be taken into account. 
The idea of rule utilitarianism is to remove the arbitrary aspects of the utilitarian analysis. It provides a measure of universality by introducing a rule of behavior between the individual and the conduct. The system separates the individual agent more from assessment of the morality of the act because she merely has to conform to some rules handed down on authority. Some argue this characteristic makes rule utilitarianism even more objective in use.

\section{Act Utilitarianism}

In contrast to rule utilitarianism, act utilitarianism does not approve of rules to assess the consequences of acts. Each individual action with its own specific details and facts should be subjected to utilitarian analysis. Utilitarian rules are generalizations of past examples, and some particular future instance may prove to be an exception to the rule. Consider the case of insider trading. In each case, the set of information and circumstances may be different. To determine the ethics of the conduct we should calculate the effects of a particular trade on a particular set of insider information. The effects will be, in part, similar to those of any trade on insider information, but they also will be in some measure, different. If we do not do a utilitarian analysis, we may not discover there are non-conventional facts about a particular insider trading case. Insider trading, as a rule, is unethical. However, some future instance may not fall under this rule. In that particular case, the act utilitarian claims that insider trading may, in fact, be morally permissible.

\section{Other Forms of Utilitarianism}

Another form of utilitarianism is preferential or preference utilitarianism. This approach takes into account the preferences of individuals involved, except where those preferences come into direct conflict with the preferences of others. Right action, in this case, is determined by maximizing the satisfaction of the preferences of those involved. This method overcomes the criticism that people have different ideas of happiness.

Critics argue both hedonism and preferentialism present subjectivist notions of well-being. To counter the subjectivism, the perfectionist form of utilitarianism is said to have a more objectivist notion of well-being. In this system, there is some type of objective list of properties that characterize a good life. Among the items on the list are knowledge, close relations, friendship and achievements of various kinds. According to perfectionism, well-being increases when a person acquires vital knowledge, friends or achievements.

These systems, while subtly different from the original, all take from Bentham the idea that utilitarianism starts with facts and claim only consequences of pleasure are to be admitted to an objective system of ethics. The finessed system, if consistent and coherent, must look something like Bentham's. Attempts to change it without changing the first principles result in systems less coherent and no better for providing a foundation for ethical obligation. So it is that Bentham remains the most consistent utilitarian. ${ }^{11}$

\footnotetext{
11 Montague Brown, The Quest for Moral Foundations (Georgetown University Press 1996) 62.
} 


\section{The General Utilitarian Analysis}

Using the utilitarian approach, a decision-maker faced with an ethical choice proceeds along these general steps. ${ }^{12}$

1. Consider the conduct to be evaluated. In stating the conduct, it is best to state it in as morally neutral language as possible so as not to bias the evaluation.

2. Identify those directly and indirectly affected by the conduct. The evaluator should try to spread the net as widely as practicable. Many of our actions affect society as a whole. For example, insider trading has systemic effects. If the public realizes that individuals have access to non-public information, then the integrity of the market is compromised.

3. Evaluate the good and the bad outcomes of the conduct on the individuals and entities identified in (2) above. Start with the consequences on those immediately affected. Identify the most striking consequences first. Sometimes these may be so profound that further analysis is unnecessary because these outstanding consequences clearly show the act is unethical or ethical.

4. Extend the outcomes as far into the future as possible. Judgment is of course required because the further the forecasts go into the future, the less reliable they become.

5. Weigh the total good versus the total bad outcomes with due consideration given to the quantity, duration, propinquity, intensity and purity of each value and the relative importance of these values.

6. Sum up all the good and bad consequences. If the conduct produces more good than bad, then the conduct is ethical. If the conduct produces more bad than good then the conduct is unethical.

7. Consider an alternative action or actions.

8. Perform a utilitarian assessment of the alternative or alternatives.

9. If the evaluation demonstrates one of the alternatives produces more good than bad, then choose this action.

10. If the evaluation demonstrates the alternatives all produce more bad than good, then choose the conduct that produces the least bad.

It is important to stress we cannot expect mathematical precision in the utilitarian calculation and approximations are acceptable especially if they are noted explicitly. The evaluator should be as objective as possible but need not convince herself of the objectivity of her analysis. Still, some find the analysis above to be complex and difficult in terms of getting the accurate facts.

\section{Criticisms of Utilitarianism}

One common criticism of utilitarianism is that no one has the time to calculate all the consequences of an action prior to acting or refraining from acting. As humans, we are constantly faced with ethical decisions, especially in the workplace. In finance, professionals encounter a myriad of situations that require ethical choices. It is not practical to expect people, particularly busy professionals to take time to weigh utilitarian choices.

\footnotetext{
12 De George (n 9), 67-70.
} 
This criticism is taking utilitarianism to the extreme because utilitarianism does not require we calculate all the consequences before we act. There is an ethical history of humankind on which we can rely. For instance, we know murder is wrong. We need not keep doing a utilitarian analysis to determine the ethics of murder. What the utilitarian method does provide the practitioner is an analytical framework to support the argument that murder is morally wrong. We know what to investigate and the analysis to undertake to determine if an act is right or wrong. When the ethics of an action is uncertain, there is a system to help analyze and resolve the issue. While there are not a plethora of moral problems, when one does arise, we can use the principles of utilitarian theory to arrive at a solution.

Another common criticism of utilitarian theory is that we cannot know the full results of any action. There are many individuals and parties who may be affected by an action and it is unrealistic to expect a decision-maker to include every affected entity. The consequences of actions may persist for an almost indefinite period of time. In addition, the calculation is likely to be inaccurate because we are unable to precisely assign values to the good and bad outcomes and weigh them correctly.

Most utilitarians concede it is impossible to give exact measures in practice. However, we can do a lot in practical life to arrive at reasonable approximations. As reasoned above, in judging most actions there is the benefit of knowing the consequences of similar actions done in the past. The utilitarian approach does not require mathematically precise calculations. This usually is not possible in cases dealing with the morality of actions. In the more standard cases the consequences are sufficiently obvious. The good or bad is sometimes so clear that accuracy is not necessary. In complex cases, where accuracy is in doubt, the evaluator should be ready to revise the analysis if she discovers the calculation is flawed. This characteristic is not a defect of the theory but a statement of the human condition and the nature of morality. ${ }^{13}$ As stated earlier, the expectation of precision is an outcome of scientism and the incorrect imposition of the scientific method on ethics.

A third criticism of utilitarianism is the theory does not account for justice and may even give a different conclusion than one from the perspective of justice. John Rawls argues that utilitarianism does not take seriously the distinction between persons. The impersonal approach championed by utilitarianism may trample the rights of individuals in the name of some greater good.

Criticisms of ethics in general and distinct ethical theories in particular usually use examples of extreme moral quandaries to prove the shortcomings of both. Yet, ethical issues are usually rather standard and not of the "moral dilemma" category. In most cases, both justice and utilitarianism will agree on which actions are just. It is only when there is divergence of results that these cases should be treated separately, as special cases. A moral analysis using justice theory or utilitarian theory results in similar moral judgments in most cases. This conclusion should not be surprising because utilitarianism is an attempt to systematize and provide reasons for moral judgments based on rationality. The same can be said of the next system of ethical thought, deontological theories.

13 De George (n 9), 70. 


\section{DEONTOLOGICAL THEORIES}

The term deontology derives from the Greek world deon, meaning duty. Deontological theories are duty based. The duty here is to our moral obligations. We are duty bound to act in accordance with our moral obligations, which are enunciated in moral principles. In contrast to utilitarianism, deontology denies an action is judged good or bad depending on its consequences. Deciding an act is ethical or unethical depends instead on whether it follows or violates a moral principle. Therefore, some acts are always wrong, even if the act leads to a positive outcome.

There are two major steps in the deontological framework:

1. Determine the moral principles, an example of which is, "it is wrong to kill."

2. Act according to these moral principles because it is your duty to do so.

Logically therefore, there must be a way of determining these moral principles to which we are obliged to adhere. There are so far, two main ways to determine moral principles. The method depends on the specific deontological system. Examples of the main deontological moral systems are:

1. The Judeo-Christian tradition.

2. The Islamic tradition.

3. The Greek Stoic tradition.

4. Kantian Ethics.

In the religious traditions of Judaism, Christianity and Islam, moral principles derive from God who reveals these principles to followers. Moses received the Ten Commandments, Jesus Christ gave his moral teachings during the Sermon on the Mount and the Prophet Muhammad (Peace Be Upon Him) received Allah's moral laws over the course of 23 years. In the religious deontological tradition, morality ultimately rests on God who reveals the moral law (consisting of moral principles) to followers.

Greek Stoic philosophy maintains that moral principles are found in natural law. For Stoics, god is in nature and, primarily, the immanent principle governing the world. Good is inherent in human nature and it is through human rationality that we are able to recognize the good. This doctrine, described earlier, defines the Natural Law approach to ethics. According to the Stoics, the universe has a rationality and a purposeful order. Human lives harmonize with this purpose and as such, humans have a divine spark that helps them to live in accordance with natural law. Moral principles, therefore, are part of the natural law but recognizable through human reason.

The religious deontological tradition is grounded on the divine while the Stoic tradition is grounded in natural law. Immanuel Kant formulated the most influential secular approach to deontological ethics. Kantian moral principles are given not by a divine being, but are grounded in human reason. Kant was influenced by science and stands at the height of European Enlightenment, an intellectual period famous for the attempt to go beyond authority and superstition and deal with the world on the basis of human reason.

Kant gives three propositions that delineate his ethical system:

1. A moral agent's action is moral only if the agent does it from a sense of duty.

2. A moral agent's action is moral only if the agent acts on the basis of a principle or maxim. 
3. It is a moral agent's duty to act out of reverence for the moral law.

Clearly, three elements are crucial in Kant's ethics. First, the moral agent is a person who performs an action and has the capacity to act morally. Normally, we say an agent needs to be free to be able to make moral choices, otherwise she cannot be blamed or praised for the act she chooses. Freedom is a prerequisite for morality. In contrast, Kant points out that the experience of the moral law leads to an awareness of freedom. A person experiences freedom when she reflects on the ability she has to make a moral choice.

Secondly, a maxim is a principle or general rule governing the action of a rational person. For instance, "It is wrong to commit murder" is a moral principle. Maxims are critical in Kant's ethics because they are the basis on which the will operates.

Thirdly, the desire to do one's duty in upholding and acting on moral principles comes out of the will. This is the faculty of deciding, choosing and acting. Kant's moral theory starts with the phenomenon of "good will" and celebrates what can be achieved by the application of human reason. We exercise good will when we act according to moral principles and the autonomous will is the source of moral action.

For Kant, in the realm of moral obligation, morality implies a categorical imperative. We do what we must because of our duty to follow the moral law. A categorical imperative tells us to do something without any reference to the likely result. In contrast, a hypothetical imperative tells us to do something in order to reach a desired end. An example of a hypothetical imperative is, if you are thirsty, then you should drink some water. All hypothetical imperatives come in the form of an "if . . then" statement. Kant did not think there was anything moral in acting to achieve a particular end. Kantian ethics is a priori and is established apart from the consideration of consequences. This approach is diametrically opposed to utilitarianism.

\section{The Categorical Imperative}

Kant uses the categorical imperative to test if moral principles or acts are right. He gives three formulations of the categorical imperative.

First Formulation: act only according to that maxim whereby you can at the same time will that it should become a universal law without contradiction. ${ }^{14}$

Put simply, Kant means that something is right only if you can, without contradiction, wish it to become universal law. This formulation provides a simple logical test. If we are content that everyone else should be bound by the same principle upon which we are acting, then what we are doing is logically consistent and therefore, right. Kant illustrates this using the example of keeping promises. Suppose X needs a loan from Y but will only get the loan if she promises to repay it. However, she knows she will not be able to repay the loan. Should $X$ then promise to repay $\mathrm{Y}$ with this knowledge? Kant argues we would be right to make a promise we cannot keep only if this principle - "make promises you cannot keep" - can be made into a universal law. Yet, this principle involves a contradiction, because promise-making becomes nonsense

14 Immanuel Kant, Groundwork of the Metaphysics of Morals (Cambridge University Press 2012) 44. 
if everyone is entitled to break their promises. Thus, Kant says it is always wrong to make a promise we know we cannot keep. ${ }^{15}$

Second Formulation: act in such a way that you treat humanity, whether in your own person or in the person of any other, never merely as a means to an end but always at the same time as an end. ${ }^{16}$

We have a perfect duty to not use others or ourselves merely as a means to some end. Each human is a rational being who is valuable, possesses dignity and is worthy of respect. Therefore, we should treat each person as an end, with respect and dignity. Rational beings are not objects to be used as a means to someone's subjective ends. Take the example of X and promise keeping in the loan situation given above. If $\mathrm{X}$ takes the loan and makes a promise she intends to break, then $\mathrm{X}$ does not treat $\mathrm{Y}$, the creditor, as an end but as a means to an end - which is to get funds.

Third Formulation: therefore, every rational being must so act as if he were through his maxim a legislating member in the universal kingdom of ends. ${ }^{17}$

The 'kingdom of ends' is the society of rational beings. Rational beings also are autonomous and must be treated as such. Morality cannot be imposed on others but must be self-imposed. In other words, the third formulation tells we are rational beings capable of conceiving and understanding the moral law and as rational beings we knowingly and willingly act in accordance with the moral law. Because reason is the same for all rational beings, we each give ourselves the same moral law.

Going back to the example of promise keeping given above, $\mathrm{X}$ should not make a promise she intends to break to $\mathrm{Y}$. In doing so, $\mathrm{X}$ does not treat $\mathrm{Y}$ as an autonomous person. $\mathrm{Y}$ is a rational being who does not wish to be on the receiving end of a broken promise. The moral principle, "make promises you cannot keep" would not be legislated by Y. Nor would it be legislated by $\mathrm{X}$. The test of the morality of a principle is not whether people accept it but whether all rational beings should accept it regardless of whether they are agents or receivers of the actions. ${ }^{18}$

\section{Moral Law versus Moral Principles}

Note the categorical imperative does not tell you the content of your moral obligations. It is a first order principle of pure practical reason or reason as applied to action. The categorical imperative provides the criteria against which we can test whether an action or a second-order principle is moral. A second-order principle is for example, the moral principle that states "Lying is wrong." This principle proposes a moral norm or rule, applicable to all and binding on all unconditionally. However, this second-order principle has content and is in accord with the categorical imperative, which Kant calls the moral law.

As first stated in the beginning of this section, deontology requires two elements: moral principles and a duty to follow them. The moral principles derive from two main sources,

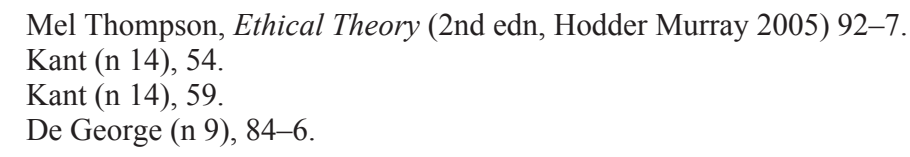




\section{Table $1.1 \quad$ The foundations of moral principles in deontological ethics}

\begin{tabular}{llll}
\hline Moral Principle & Christian Deontology & Islamic Deontology & Kantian Deontology \\
\hline $\begin{array}{l}\text { Do not steal } \\
\text { Do not cheat }\end{array}$ & $\begin{array}{l}\text { The principle(s) is (are) } \\
\text { revealed by God so we } \\
\text { are obliged to follow the } \\
\text { principle(s) }\end{array}$ & $\begin{array}{l}\text { The principle(s) is (are) } \\
\text { revealed by Allah so we }\end{array}$ & $\begin{array}{l}\text { The principle(s) conform(s) to the three formulations } \\
\text { are obliged to follow the } \\
\text { principle(s) }\end{array}$ \\
& & $\begin{array}{l}\text { - It can be made a universal principle without } \\
\text { contradiction }\end{array}$ \\
& & $\begin{array}{l}\text { - It does not treat others as means } \\
\text { - It respects the autonomy and dignity of rational } \\
\text { beings and will be legislated as a principle by all } \\
\text { rational beings }\end{array}$ \\
\hline
\end{tabular}

a divine, supreme being or human reason. We need to know if a particular principle is moral and can test the principle or principles as shown in the Table 1.1. The principles probably most relevant in financial ethics are, "Do not steal," "Do not cheat" and "Do not lie." If we test these principles against religious deontological systems, we find God and Allah issue these commandments and adherents to these faiths should obey them. If we test these three principles against the three formulations of Kant's categorical imperative or what he calls his moral law, then we observe the principles are all in accord with the formulations. Therefore, these principles are morally correct norms. It is our duty to practice these principles. In sum, deontology is an ethical system that proposes we have a moral obligation to follow the commands of moral principles.

\section{Criticism of Deontological Theories}

A common criticism made against deontological theory, particularly against the Kantian version, is that there will be regularly in practice conflicts between moral principles. When such conflicts arise, we find ourselves in a moral dilemma.

A common example of a conflict of moral principles is the dilemma of the battered wife and her murderous husband. The wife runs away from her husband whom she believes will kill her. She tells you she is going to her mother's house to hide. The husband comes to you and asks you where his wife is. You believe if you tell the truth, the husband will kill his wife. However, if you lie, you will be breaking the moral principle of not lying. What should you do?

There are two ways to resolve the dilemma. The first is to make an exception to one of the principles in conflict so as to give a resolution to the conflict. For instance, we construct the principle of allowing a person to lie to save the life of a person. We test the principle with this exception against the three formulations of the Categorical Imperative. If the principle passes the tests, then it is moral. We may make exceptions in both the conflicting principles and test both with their exceptions to find out which is right. However, the answer may not always be obvious and we may need to give arguments to justify the correct principle.

The second way out of a moral dilemma is to view each of the conflicting principles as prima facie moral rules. ${ }^{19}$ A prima facie rule is one that is in general binding. When there is only one prima facie rule that applies in any particular situation, then we are morally bound to obey the rule. However, when several prima facie rules apply, or when we cannot fulfill every one of them, then not all of the rules are morally binding. The actual moral duty that is binding

19 De George (n 9), 88-9. 
in the multiple rule situation is the one appropriate in that particular case. We decide which is the morally binding rule by seeing which takes precedence. Reasons must be given why one rule takes precedence over the other or others.

In the case of the murdering husband, the moral principle, "Do not aid in murdering a person" trumps, "Do not lie." The reason is clear: a human life is measured against harming someone in a non-life-threatening way. The principle that takes precedence, "Do not aid in murdering a person," therefore, is the one we have a moral duty to follow.

When moral principles clash, it is often difficult to decide which takes precedence. In these cases the individual and society should carefully and as objectively as possible consider the various arguments in support of opposing views. When a clear decision is not possible, then the position with the strongest argument should be chosen.

\section{JUSTICE THEORIES}

Justice is an ancient concept. Plato's Republic is concerned with what is meant by justice. For Plato, justice is to find that right balance of emotions, reason and appetites within the human person and to know the right place of oneself and others in society. It is better to be just than unjust because, as Plato explains, a person who is unjust is driven by desires, which are usually numerous and somewhat unsatisfiable. The unjust are swayed by their appetites, which are temporary means of staving off loss and discontent. Consequently, the unjust person is invariably frustrated. It also is better to be just than unjust because the just are ruled by reason and reason deals with eternal values. Therefore, the just person possesses greater satisfaction even if he seems a failure in the conventional sense.

For Plato's most eminent student, Aristotle, justice is the supreme and complete virtue because it is the sum of all virtues. For instance, a coward is unlikely to be just, nor is a miser. Instead, a brave, generous person is more likely to be just. Aristotle distinguishes two forms of justice: distributive and corrective justice. Distributive justice concerns the distribution of honor, wealth and other items. Distributions count as just if equal persons receive equal shares. Clearly, just distributions require a determination of worth of the persons and worth of the thing being distributed.

Distributive justice concerns the distribution and burdens by the state, so that everyone receives her due. The great debate is over what is considered fair distribution. Some, such as Thrasymachus, an interlocutor in Plato's renowned dialogue, the Republic, argue that justice is in the interests of the stronger. So the strong, the rich, the powerful should receive a larger proportion of benefits. In contrast, some argue that everyone should be treated equally. John Rawls (1921-2002) an American moral and political philosopher developed a well-respected theory of distributive justice.

Corrective justice is concerned with restoring the equality between people when one has wronged the other. In corrective justice, the worth of the person does not matter. What does matter is correcting the difference of what is lost by the victim to the perpetrator. Corrective justice seeks to restore equality by taking away the perpetrator's gain and restoring it to the victim. 
From the descriptions above, we observe a definition of justice, in the broadest sense, it is giving each person her due, treating equals as equals, and unequals unequally. ${ }^{20} \mathrm{We}$ often think of the term as synonymous with law or lawfulness. A broader sense of the word is closer to fairness. Behavioral finance studies show that people have an inherent sense of justice or fairness. This view of human nature clashes with the classical economic view of "homo economicus", which views humans exclusively as self-interested.

There are other forms of justice besides the two Aristotle describes. Compensatory justice requires compensating someone for a past injustice or making good some harm suffered in the past. People should be fairly compensated for their injuries by those who have injured them. This kind of justice may be and often is served through monetary compensation.

Retributive justice is punitive because it is the punishment due to someone who breaks the law or has committed harm to others. The punishments must be fair, just and in proportion to the wrongdoing. In general, relevant criteria for deciding the level of punishment are the seriousness of the crime and the intent of the criminal.

Commutative justice belongs in the sphere of transactions and is, therefore, particularly relevant to finance and business. This form of justice calls for fundamental fairness in all agreements and exchanges between individuals or private social groups. In the exchange of goods and services, sellers should set fair prices and not practice price gouging. To ensure fair pricing in transactions, there must first be full informational disclosure to both buyer and seller. Crucially, both parties in the transaction must enter it freely and not be forced to do so. In commutative justice both parties also should see some benefit from the transaction.

Procedural justice concerns fair decision procedures, practices or agreements and is relevant in the fair resolutions of disputes. There must be fairness and transparency in the processes by which such decisions are made. Fair procedures are necessary for equitable outcomes. This form of justice is important in the concept of due process in law.

\section{Principles of Justice}

Rawls is well known for his theory of distributive justice. His theory uses social contract theory and is Kantian in its approach in applying the third formulation of the categorical imperative. The social contract theory, first put forward by Thomas Hobbes, is a theoretical concept. Its basis is the need of the individual to be secure and to maximize necessities and aspirations through cooperation with others. Individuals decide to live together in a society and cooperate to better provide for everyone's needs. The members of the society agree on certain rules everyone must observe, and on ways to enforce these rules. It is this agreement that is called the social contract. The social contract underlies an individual's obligation to act with benevolence towards the others in the group and to follow the rules designed to ensure unselfish behavior.

The principles of any society are ones that all rational beings would agree to, as the third formulation of the categorical imperative proposes. Rawls agrees with Kant that individuals in a society are rational beings with autonomy. As such they will freely agree to adhere to the principles upon which they have legislated as rational beings. The members of a society decide on the principles in a Rawlsian hypothetical situation, which he calls the "original position."

\footnotetext{
20 De George (n 9), 97.
} 
The original position is not an actual fact at any time, but is one we adopt by putting on the "veil of ignorance." To wear the veil of ignorance is to pretend not to know one's actual position in society, whether one is rich or poor, young or old, healthy or sick, Chinese or Hispanic, male or female and so on. Self-interest, operating behind the veil of ignorance, leads to the formulation of Rawls' two principles of justice.

\section{First principle of justice}

This is the principle of equal liberty. "Each person is to have an equal right to the most extensive basic liberty compatible with a similar liberty for others." ${ }^{21}$ This principle is not chosen because of the belief that everyone should be treated equally. Rather, the members of the society legislate it because behind the veil of ignorance no one knows her position in society. She would want therefore, to be treated equally with people in higher stations in life if she finds herself in a lower place. This first principle is prior to the second and must always be considered the ideal.

\section{Second principle of justice}

This is the principle of equality. "Social and economic inequalities are to be arranged so that they are both (a) to the greatest benefit the least advantaged and (b) attached to offices and positions open to all under conditions of fair equality of opportunity." 22 This principle concerns the distribution of wealth and power. Inequalities are inevitable and can actually lead to improved conditions for all. These inequalities are acceptable to all only if the least advantaged group is better off as a result of them. In addition, the second principle ensures the least advantaged should not be denied equal opportunity. For example, take two financial institutions $\mathrm{A}$ and $\mathrm{B}$. A is more unequal than $\mathrm{B}$ but the least disadvantaged in $\mathrm{A}$ has an income of 100. This is because the company hires and pays for the best people in the business in order for the business to be a great success. B is a financial company that is admirably equal, where every member has an income of 80 . Clearly, the least advantaged in A is doing better economically than the least advantaged in B. Thus, from the point of the least advantaged, it is still better to be a member of company A than B.

Another example to consider is insider trading. This activity can be a violation of Rawlsian distributive justice in regards to the right of equal information for all traders. Under the veil of ignorance, traders will agree not to engage in insider trading because they do not know if they will be the least advantaged in the market, the ones without inside information. Non-insider traders will avoid being at the mercy of someone else with insider information. Therefore, if the principles of the market are determined using Rawls' original position and veil of ignorance, insider trading violates the principle of equality of information access.

Justice concerns fairness and giving individuals what is due to them. Questions of justice occur when one person is treated differently from another. The ethics of insider trading emerges from the question of fairness: should someone profit because she has privileged access to information while others in the market do not? These others may work hard on doing fundamental equity research. Yet they are outdone simply because of their unprivileged positions, lack of wealth or deficiency in connections. Many tend to think that in a just society, people can improve their circumstances through hard work.

21 John Rawls, Theory of Justice (Belknap Press 1971) 60.

22 Rawls (n 21), 83. 


\section{VIRTUE ETHICS}

Virtue ethics dates back to the Greeks (again). The tradition was the dominant philosophy during the classical period. The most celebrated virtue ethicist and perhaps the starting point of discussion for most virtue ethicists is Aristotle. In the Nicomachean Ethics, Aristotle refines and formulates a sophisticated theory that is a prototype for contemporary virtue ethics.

Virtue ethics refers to an approach to ethics that has as its central focus the judgment of character. A person's character is made up of all her virtues and vices. A person who is honest will generally act honestly even if tempted to do otherwise. Virtues are character traits Aristotle calls dispositions. A disposition to be honest is instilled when young through regular practice. By constantly choosing to act honestly, the disposition to be honest eventually forms into a habit. This habitual honesty develops into a character trait and becomes part of a person's character. This same process of habituation applies to other virtues such as generosity, courage and moderation. The person who possesses the virtues and practices them is the virtuous person.

The focus on a person's character means the virtue ethics approach is agent-centered (the decision on whether an act is right or wrong depends on the person who does the act) rather than act-centered (the rightness of the act depends on the act itself and does not take into account the character of the person performing the act). The alternate focus on the agent differentiates virtue ethics from utilitarian and deontological ethics, both of which are act-centered. There are three versions of this agent-centered focus. ${ }^{23}$ First, the moderate version views most of morality as connected with character, although some actions can be evaluated independently of virtue. Secondly, the reductionist version has all judgments of rightness being reducible to judgments of character. Lastly, there is the replacement version, where the virtuous notions gain priority by default, after the deontic concepts have been eliminated.

All three versions of virtue ethics are formulated through the idea of a virtuous character - the moral goodness of persons is determined by the virtues they possess. Instead of asking, "what should I do?" as deontological and utilitarian ethics do, virtue ethics considers what sort of person the moral agent should be and what sort of life she should lead. This question is not answered by consulting principles, norms or policies that apply to situations. Rather, the question is answered by considering the person's character along with other morally salient features of the situation. According to most virtue ethics theories, the virtuous do not act virtuously for the sake of being virtuous. Rather, an honest person, say, tells the truth because she loves the truth. ${ }^{24}$

The virtuous express who they are when they act, and in acting, they develop their characters. While the moral evaluation of the person is different from the moral evaluation of an action, nevertheless, the evaluations are related. A virtuous person refrains from immoral acts. So, for instance, a truthful person does not lie, and an honest person does not cheat.

Deontological and utilitarian theories have the notion of right and wrong acts. The theories represent our legalistic approach to ethical thinking. There is an emphasis on rules and laws, implying correct answers to ethical questions. By contrast, according to virtue ethics, especially in the replacement version, the recommended method in ethics is an Aristotelian one,

\footnotetext{
23 Daniel Statman, "Introduction to Virtue Ethics," in Daniel Statman (ed), Virtue Ethics: A Critical Reader (Georgetown University Press 1997) 7.

24 Stan Van Hooft, Understanding Virtue Ethics (Acumen Publishing 2006) 11.
} 
in the sense that we can expect no precise answer to practical questions. Virtuous people may therefore, arrive at different answers to the same practical problem.

\section{Virtues}

Arete is the Greek word for virtue and can also be translated as "excellence." Aristotle's definition of virtue is that it is a state (hexis) of one's character. ${ }^{25}$ This is equivalent to the definition with virtue being a "character trait." A hexis or character trait is a settled state that involves reason and emotion. A person is honest and does honest deeds "readily, eagerly, unhesitatingly, scrupulously, as appropriate." ${ }^{26}$ Each of the virtues involves getting things right, for each involves practical wisdom (or in Greek, phronesis), which is the ability to reason correctly about practical matters. For Aristotle (some contemporary philosophers disagree), all virtues are morally good.

For Aristotle a virtue is the "mean between extremes," something more than the Greek emphasis on moderation. Aristotle is clear that the excess or deficiency of a virtue is not the virtue itself. Virtue is the mean between excess and deficiency. Courage is the mean between timidity and recklessness. Temperance is the mean between gluttony and prudishness. To judge what is the mean requires reason and knowledge - these excellences are the guides to our virtues.

David Hume is one of the two important modern virtue theorists. The other, who has special significance to business and the free enterprise system, is Adam Smith (1711-76). Both defended a portrait of human nature in which "sympathy" and "fellow-feeling" play roles as important as self-interest. For Hume and Smith, virtues are important because they are both useful and pleasing. In Smith's Theory of the Moral Sentiments, published before the (currently viewed) capitalist manifesto, Wealth of Nations, he places great store on the two basic virtues of modern market society - justice and benevolence. Followers of Adam Smith's economics often ignore his ethics, but the economics is not workable without the ethics.

There is another ancient virtue ethicist who may have been more influential than Aristotle, Hume, or Smith. Confucius (551-479 BCE) is the foremost Chinese proponent of virtue ethics, emphasizing virtues such as good upbringing, good habits and good instincts. Confucius taught the way to universal harmony (Tao) through right action (Jen) in harmony with others (Yi). The virtues, particularly the virtue of "filial piety," are central to this vision.

According to Aristotle, Confucius, Smith and Hume, virtues are cultivated responses and actions, which may, at the time require no deliberations whatsoever. ${ }^{27}$ While deontology may require some reasoning for us to act on principle and utilitarianism encourages the calculation of utilities, the manifestation of virtue seems to require little or no thought. A virtuous person acts on a virtue naturally as the circumstance arise. The truly honest person for example, does not need to think about acting honestly. She never even considers lying. The virtues, accordingly, do not require deliberation. Indeed, too much deliberation, for example should I give a loan to a friend who needs monetary assistance, is evidence one does not have the virtue of generosity. Virtues may blur the distinction between altruism and selfishness, a duality

\footnotetext{
25 Rosalind Hursthouse, On Virtue Ethics (Oxford University Press 1999) 28-9.

26 Ibid.

27 Robert C. Solomon, "Business Ethics and Virtue," in Robert E. Frederick (ed), A Companion to Business Ethics (Blackwell Publishing 2003) 35-6.
} 
often discussed by moral philosophers. A generous person may act generously not because of concern for the well-being of others but because she may simply be generous and/or take pride in being generous. To be generous is to act and be motivated by generosity, but no further claim needs to be given to distinguishing self-interest, altruism and concern for others. ${ }^{28}$

Hursthouse, who is an adherent of the Aristotelian version of virtue ethics, gives a general way to determine virtues. She neatly summarizes the premises that underlie the virtue ethics approach to right action in the following way: ${ }^{29}$

P.1. An action is right if and only if it is what a virtuous agent would characteristically (i.e. acting in character) do in the circumstances.

P.1a. A virtuous agent is one who has, and exercises, certain character traits, namely, the virtues.

P.2. A virtue is a character trait that ...

The second premise, P.2., is completed by giving a list or a criterion. In the Second Enquiry Concerning the Principles of Morals, David Hume completes P.2 such that: 'A virtue is a character trait that is useful or agreeable to its possessor or to others. Hursthouse completes P.2. in an Aristotelian manner: a virtue is a character trait that a human being needs for eudaimonia, roughly translated as happiness.'

\section{Eudaimonia}

Hursthouse says, "a virtue is a character trait a human being needs for eudaimonia, to flourish or live well." ${ }^{30}$ Eudaimonia is a Greek word that roughly translates as "happiness," "flourishing" or "well-being," although each translation has its drawbacks. Happiness, in its contemporary understanding, connotes something subjective. Flourishing does not have this subjectivity problem but its drawback is that we may have a mistaken idea of what flourishing consists of, pleasure for instance. Well-being does not have a corresponding adjective, and is therefore clumsy to use. Hursthouse proposes that the notion of eudaimonia is close to the idea of "true (or real) happiness," or "the sort of happiness worth having." 31 We would want this sort of happiness for our children for their own sakes.

Eudaimonia is an expression of a form of naturalism. In other words, we can (to a certain extent) use an account of human nature to base our understanding of virtue on. The virtues are those character traits that make a human being a good human being. "Ethical evaluations of human beings as good or bad are taken to be analogous to evaluations of other living things as good or bad specimens of their kind. The analogy is instructive, because it reveals that several features of ethical evaluation thought to be peculiar to it, and inimical to its objectivity, are present in the quasi-scientific evaluation even of plants." 32 Human beings need those character traits to live well as human beings, to live a good, characteristically human life.

\footnotetext{
Solomon (n 27), 35.

Hursthouse (n 25), 28-9.

Hursthouse (n 25), 10.

Hursthouse (n 25), 12.

32 Hursthouse (n 25), 21.
} 


\section{Research handbook on law and ethics in banking and finance}

\section{Criticism of virtue ethics}

Virtue ethics generally begin within an established tradition or culture that uphold traits which are admired in that tradition or culture. This cultural aspect of virtues gives rise to the criticism that virtue ethics is relativistic. Relativism is the idea that there may be very different virtues in different societies. How are we to decide which virtues are true?

Indeed, different virtues are praised in say, Homeric Greece versus the medieval period of Thomas Aquinas, versus the Confucian era and contemporary corporate Asia. However, it does not follow that there are not some non-relative virtues. These virtues are found in every human society or institution, just because, as Hursthouse argues, we are human. Thus, we consider trustworthiness and honesty to be virtues because they are crucial to almost any human interchange. The non-relative virtues are essential in all societies because we require them in order to cooperate and live together. We need to supply society with the necessities of life, protect society from others who would do harm and from natural disasters. All this suggests there are non-relative virtues, perhaps with local variations and interpretations, such as courage, honesty, generosity and congeniality. In finance, trustworthiness, fairness and cooperation are particularly important non-relative virtues because they undergird any form of market or non-market society.

\section{CONCLUSION}

The moral philosophical canon dates back 2,500 years. In contrast, Modern Finance Theory is about 60 years old. With 2,500 years of research, analysis, rigorous criticism and scholarship it seems reasonable to conclude that the discipline of ethics is more fully formed than the nascent field of finance. Why then, should the methods of ethics be ignored when issues of right and wrong invariably arise in financial practice? Indeed, the integration of ethics into the field of finance is more than likely to improve financial theory and increase the understanding and application of frameworks and concepts that moral thinkers have designed and refined in the last two millennia. 